\title{
Correction to: When Politicians Talk
}

\author{
Ofer Feldman
}

\section{Correction to: \\ O. Feldman (ed.), When Politicians Talk, https://doi.org/10.1007/978-981-16-3579-3}

The original version of the book was inadvertently published with spell errors in Chapters 1 and 12 in chapter title and running text. The book has been updated with the changes. 